\title{
Physical and Chemical Properties of Castanopsis fargesii Wood after Heat Treatment in Sand or Vacuum Media
}

\begin{abstract}
Wen-Yu Qi, Cai Liu, Xiao-Lian Wu, Ji-Qing Li, Xin Guan,* and Jin-Guo Lin *
Castanopsis fargesii is among the most prevalent hardwood species in South China. To improve the poor dimensional stability of $C$. fargesii wood, heat treatments were performed using vacuum or sand as the medium at four temperatures from $170{ }^{\circ} \mathrm{C}$ to $215^{\circ} \mathrm{C}$ for $4 \mathrm{~h}$. As a medium, vacuum or sand can create a low oxygen environment. The results showed that, as the temperature increased, the oven-dry density decreased, whereas the dimensional stability and the total color change $\left(\Delta E^{*}\right)$ increased with both media, two different changing patterns of $a^{*}$ and $b^{*}$ were observed, the lignin content increased, and the holocellulose content decreased. The oven-dry density decreased $9.4 \%$ and $25.5 \%$, volume shrinkage ratio decreased $27.8 \%$ and $37.7 \%$, and the $\Delta E^{*}$ was 19.63 and 45.52 , the lignin contents increased from $17.62 \%$ to $28.62 \%$ and $42.87 \%$, and the holocellulose contents decreased from $80.49 \%$ to $69.43 \%$ and $51.04 \%$ when $C$. fargesii wood was heated under vacuum and with sand at 215 ${ }^{\circ} \mathrm{C}$, respectively. Overall, sand heat treatment affected wood physical and chemical properties more than vacuum heat treatment. The analysis of functional groups and crystallinity also showed that there were severe changes in $C$. fargesii wood under sand heat treatment.
\end{abstract}

Keywords: Castanopsis fargesii; Heat treatment; Shrinkage; Color; Chemical properties

Contact information: College of Material Engineering, Fujian Agriculture and Forestry University, Fuzhou 35002, Fujian, China; *Corresponding authors: guanxin1001@sina.com; fjlinjg@126.com

\section{INTRODUCTION}

Wood is the only natural polymer of the four main construction materials (steel, cement, plastic, and wood) and it has good environmental properties, such as visual characteristics, tactile characteristics, audio characteristics, and temperature and moisture control characteristics. In addition, wood is renewable and environmentally friendly, which has made wood one of the most popular materials in the world. Further, wood has outstanding advantages in energy consumption and environmental protection (Li et al. 2017). However, some species of wood have defects, such as low dimensional stability and decay resistance. Due to the loss of forests (Lin et al. 2019) and increased wood demand, wood must be modified prior to use to improve its lifespan. Among all modification methods, heat treatment is favorable because it requires no additional chemicals, meanwhile it produces a beautiful color similar to a tropical style (Fan et al. 2010; Candelier et al. 2013; Okon et al. 2017). Further, heat treatment improves wood stability and service time, which may be caused by changes in chemical components (Özlem et al. 2016) and micro-structures (Wang et al. 2011; Guo et al. 2015; Altgen et al. 2018). Different media, such as steam, oil, and vacuum, are used (Esteves et al. 2009). When wood is heat-treated in a vacuum medium, it shows less degradation than that in a $\mathrm{N}_{2}$ medium at the same temperature (Candelier et al. 2012). However, the mechanical 
properties of wood might be better after treatment with $\mathrm{N}_{2}$ or vacuum than after treatment with steam or air (Rautkari et al. 2014; Yang et al. 2016; Lee et al. 2018).

The use of sand or vacuum as media creates a hypoxic environment. Several experiments have used vacuum in heat treatment. Sun et al. (2013) found that vacuum could protect the wood from oxygen and remove the volatile compounds that contribute to the degradation of the polysaccharides, which causes less degradation than other media; thus, the degree of change is less than other media. As sand is an easily obtained, fire protective, and cheap material, it has been widely used in construction. In addition, sand is used as an energy-transfer medium for cooking in several areas. Sand heat treatment works by transferring thermal energy via thermal conduction. When wood is heated, sand builds a relatively closed system that forms organic acids formed; hence, it can catalyze hydrolysis, while the volatile products are taken away in other media of the heat treatment process, such as vacuum, N2, or steam (Stamm 1956).

Castanopsis fargesii Franch is one of the most prevalent species middle subtropical evergreen broadleaved trees. It belongs to the Fagaceae family and is an important commercial timber in southern China. Sources of wood of the Fagaceae family are abundant. In Fujian Province alone, the forest savings area of Fagaceae wood exceeds $20,000 \mathrm{hm}^{2}$ (Liu 2010). Wood in the Fagaceae family, such as C. fargesii is usually used for furniture, flooring, and agricultural tools. However, C. fargesii wood has low dimensional stability and resistance to fungi decay. Therefore, C. fargesii must be heattreated to improve its quality, which results in improved stability and a beautiful color. The heat treatment of wood in a sand medium has rarely been reported. In this study, the physical properties (oven-dry density, color, and shrinkage) and chemical content of $C$. fargesii wood during heat treatment were tested. To reveal the influence of sand and vacuum media, $C$. fargesii wood was treated at the same temperature and duration for both sand and vacuum media.

\section{EXPERIMENTAL}

\section{Materials}

The $C$. fargesii wood was obtained from DaTian county in FuJian province (China). Nine trees that were 35 years old were cut from a $C$. fargesii plantation. The wood was sawn into boards of $25 \mathrm{~mm}$ in thickness and then dried in an oven at $60{ }^{\circ} \mathrm{C}$ to reach a moisture content (MC) of $10 \pm 1 \%$. The samples used for tests were cut along the tangential $(\mathrm{T})$, radial $(\mathrm{R})$, and longitudinal $(\mathrm{L})$ directions. The dimensions of the samples were $20 \mathrm{~mm}$ $\times 20 \mathrm{~mm} \times 20 \mathrm{~mm}(\mathrm{~T} \times \mathrm{R} \times \mathrm{L})$. The samples were divided into 8 treatment groups and 1 reference group, each groups contained 25 samples.

\section{Heat Treatment}

The samples of $C$. fargesii wood were heated with the media of vacuum and sand. The sand heat treatment was performed in a Model 30-1060 oven (Memmert, Schwabach, Freistaat Bayern, Germany). Sand was sieved in meshes of $0.42 \mathrm{~mm}$ and $0.85 \mathrm{~mm}$ (20mesh to 40-mesh). The samples were entirely and separately buried between sand. Vacuum heat treatment was performed in a DZF-6090 vacuum drying oven (Yiheng, Shanghai, China), in which the relative pressure ranged between $-0.02 \mathrm{MPa}$ and $0.01 \mathrm{MPa}$. The samples were treated with the same process, in which they were heated at a rate at $10{ }^{\circ} \mathrm{C} / \mathrm{h}$, and a staged heating process was adopted to ease the internal stress and avoid distortion 
and cracking. The heat treatment was applied at four temperatures $(170,185,200$, and 215 ${ }^{\circ} \mathrm{C}$ ) for $4 \mathrm{~h}$ with sand and vacuum media.

\section{Physical Properties}

Oven-dry density testing method

According to GB/T 1933 Method for determination of density of wood (2009). The samples were placed at $60{ }^{\circ} \mathrm{C}$ for $4 \mathrm{~h}$, and the temperature was raised to $103{ }^{\circ} \mathrm{C}$ for 8 $\mathrm{h}$. Then, the samples were measured every $2 \mathrm{~h}$. Between the two measurements, if the change did not exceed $0.5 \%$ of its own weight, it was considered as stable and having reached oven-dry condition.

To determine the density of samples, the oven-dry dimensions and weight of untreated and sand or vacuum treated samples were measured to $0.01 \mathrm{~mm}$ and $0.001 \mathrm{~g}$ sensitivity. The density of samples was calculated according to Eq. 1,

$$
\rho_{0}=M_{0} / V_{0}
$$

where $\rho_{0}\left(\mathrm{~g} / \mathrm{cm}^{3}\right)$ is oven-dry density; $M_{0}(\mathrm{~g})$ is oven-dry mass of each sample, and $V_{0}$ $\left(\mathrm{m}^{3}\right)$ is oven-dry volume of samples.

\section{Dimensional stability testing method}

According to GB/T 1932 Method for determination of shrinkage of wood (2009), the dimensions and weight of the samples were determined in three states, which included the saturated state, the air-dry state, and the oven-dry state.

First, the samples were soaked in distilled water, which was measured with a digital vernier caliper, and the water was changed every $3 \mathrm{~d}$ until the tangential dimension changes of the tested samples were less than $0.02 \mathrm{~mm}$ between tests.

Then, the air-dry dimensions of 3 directions were detected when the samples were put into a $20{ }^{\circ} \mathrm{C}$ and $65 \%$ relative humidity (RH) environment, and they were measured with a digital vernier caliper every $6 \mathrm{~h}$.

Finally, the samples were placed at $60{ }^{\circ} \mathrm{C}$ for $6 \mathrm{~h}$, and the temperature was raised to $103{ }^{\circ} \mathrm{C}$ for $8 \mathrm{~h}$. Then, the samples were measured every $2 \mathrm{~h}$. Between the two measurements, if the change did not exceed $0.5 \%$ of its own weight, it was considered as stable and having reached oven-dry condition. The shrinkage ratio was calculated according to Eq. 2,

$$
\beta_{\max }=\left(L_{\max }-L_{0}\right) / L_{\max } \times 100
$$

where $\beta_{\max }$ is the shrinkage ratio, $L_{\max }$ is the data from the saturated state condition, and $L_{0}$ is the data from oven-dry condition.

\section{Color testing method}

Color measurements were taken on the surface of the wood specimens via an Xrite spectrophotometer (Model Color i7, Grand Rapids, Michigan, USA) before and after heat treatment. Each group had 25 samples, and each sample was measured two times. The conditions were adjusted to $20{ }^{\circ} \mathrm{C}$ and $65 \% \mathrm{RH}$ until the specimens reached equilibrium MC before color measurements. The CIE $L^{*} a^{*} b^{*}$ system is characterized by three parameters; $L^{*}$ describes the lightness from black $(0 \%)$ to white $(100 \%), a^{*}$ represents green $(-a)$ to red $(+a), b^{*}$ represents the blue $(-b)$ to yellow $(+b)$, and $\triangle E^{*}$ means the total color difference. The data were calculated with Eq. 3: 


$$
\Delta E^{*}=\left(\left(L_{\text {treated }}^{*}-L_{\text {reference }}^{*}\right)^{* 2}+\left(a_{\text {treated }}^{*}-a_{\text {reference }}^{*}\right)^{* 2}+\left(b_{\text {treated }}^{*}-b_{\text {reference }}^{*}\right)^{* 2}\right)^{1 / 2}
$$

All the parameters tested were subjected to analysis of variance (ANOVA), and significant differences between the mean values of reference by Statistical Product and Service Solutions (SPSS IBM Version 24, Chicago, American) and the samples were determined by multiple comparison test at $\mathrm{p}<0.05$.

\section{Chemical Properties Characterization}

\section{Chemical composition analysis method}

The treated and reference samples were chopped into small pieces and milled with a Wiley mill (Moling 800Y Wuyi Haina Electric Appliance Co., Ltd, Jinhua, China) into a homogenous meal, which would be sieved in $0.25 \mathrm{~mm}$ and $0.42 \mathrm{~mm}$ (40-mesh to 60-mesh) of standard particle dimensions to chemical analysis and in meshes of 200 for chemical structure analysis. Klason lignin content was measured according to GB/T 2677.8 Fiber raw material - Determination of acid-insoluble lignin (1994), $\alpha$-cellulose was measured according to GB/T 774 Fiber raw material - Determination of acid-insoluble lignin (1989), and the holocellulose content was measured according to GB/T 2677.10 Fiber raw material - Determination of holocellulose (1995).

\section{Fourier Transform Infrared (FTIR) Analysis}

The changes in chemical structure between the samples of different treatment conditions and the reference samples were analyzed via infrared spectroscopy. The meal samples were heated to $103{ }^{\circ} \mathrm{C}$ for oven drying and then blended with $\mathrm{KBr}$ and pressed into thin pellets, which were scanned with FTIR spectrometer (Bruker Vertex 70, Leipzig, Germany) in the range of 4000 to $500 \mathrm{~cm}^{-1}$ with a resolution of $4 \mathrm{~cm}^{-1}$.

\section{X-ray Diffraction (XRD) Analysis}

The crystalline structure of the untreated and treated $C$. fargesii wood samples were analyzed by X-ray diffraction. The X-ray diffraction measurement was performed via an X-ray diffractometer (Rigaku UItima IV, Tokyo, Japan) with a diffractogram range of $5^{\circ}$ to $50^{\circ}(2 \theta)$ with a scanning of $2 \% \mathrm{~min}$. The $\mathrm{CrI}$ of the samples were calculated according to Eq. 3 the method developed by Segal et al. (1959),

$$
\operatorname{Cr} I(\%)=\left(I_{002}-I_{a m}\right) / I_{002} \times 100 \%
$$

where $I_{002}$ is the maximum intensity of the lattice diffraction angle $\left(2 \theta=22^{\circ}\right)$ and $I_{\mathrm{am}}$ is the scattering intensity of diffraction from an amorphous background $\left(2 \theta=18^{\circ}\right)$.

\section{Thermogravimetric (TGA) Analysis}

The thermogravimetric analysis was performed under nitrogen atmosphere with thermal analyzer (NETZSCH STA449F3, Selb, Germany) in order to study the degradation of the untreated, vacuum and sand treated samples. Specimens weighing 4 to $6 \mathrm{mg}$ of reference, sand $\left(200{ }^{\circ} \mathrm{C}, 4 \mathrm{~h}\right)$ and vacuum $\left(200^{\circ} \mathrm{C}, 4 \mathrm{~h}\right)$ heat-treated $C$. fargesii wood were put in aluminum crucibles and temperature was heated to $800{ }^{\circ} \mathrm{C}$ from $30{ }^{\circ} \mathrm{C}$, at a heating rate of $10{ }^{\circ} \mathrm{C} / \mathrm{min}$ and a flow rate of $30 \mathrm{~mL} / \mathrm{min}$. 


\section{RESULTS AND DISCUSSION}

\section{Physical Properties of Heat-treated C. fargesii Wood Oven-dry Density Analysis}

The oven-dry density of the heat-treated $C$. fargesii wood at different temperatures and with different media is presented in Fig. 1. With the media of vacuum and sand, the oven-dry density of the heat-treated $C$. fargesii wood gradually decreased as temperature increased, and the decline in the oven-dry density of the C. fargesii wood after sand heat treatment was much higher than that after vacuum heat treatment under the same process. A marked drop in the oven-dry density of $C$. fargesii wood appeared after $200{ }^{\circ} \mathrm{C}$ for the sand medium, whereas it did not appear in the vacuum medium. The oven-dry density of the heat-treated C. fargesii wood in the sand and vacuum media decreased $3.1 \%$ to $25.5 \%$ and $2.0 \%$ to $9.4 \%$, respectively, compared to reference group. This change pattern was similar to the findings of other research (Kubojima et al. 2000), in which density decreased as heating temperature increased. Wang et al. (2011) found that the oven-dry density only decreased $16.6 \%$ after treatment at $280{ }^{\circ} \mathrm{C}$ under vacuum. The main causes of this phenomenon were the depolymerization reactions of wood polymers. Changes in wood density depend on changes in both mass and volume. The ANOVA showed that temperature, medium, and the interaction had an insignificant effect $(\mathrm{p}<0.05)$ on the ovendry density of $C$. fargesii wood.

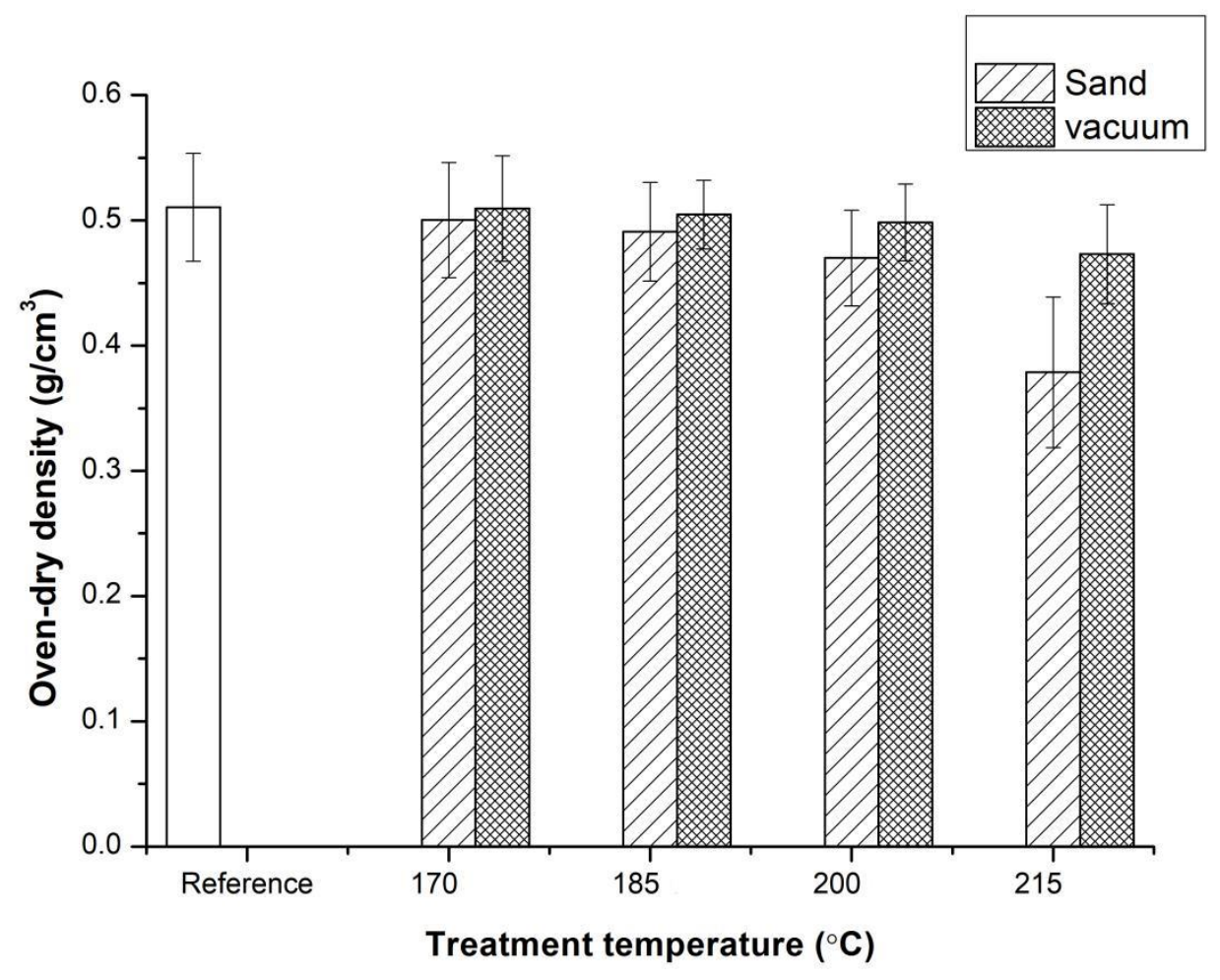

Fig. 1. The oven-dry density of heat-treated C. fargesii wood under different temperatures and with different media 
Table 1. ANOVA of Oven-dry Density for Heat-treated C. fargesii Wood under Different Temperatures and Media

\begin{tabular}{|c|c|c|}
\hline \multirow{2}{*}{ Factor } & \multicolumn{2}{|c|}{ Tangential } \\
\cline { 2 - 3 } & $\mathrm{F}$ & Sig. \\
\hline Medium & 2.235 & .111 \\
\hline Temperature & 1.478 & .232 \\
\hline $\begin{array}{c}\text { Medium } \\
\text { Temperature }\end{array}$ & .012 & 1.00 \\
\hline
\end{tabular}

\section{Shrinkage Analysis}

Figure 2 shows that the shrinkage of heat-treated $C$. fargesii wood decreased as temperature increased under both media, which indicated that the dimensional stability of the $C$. fargesii wood was improved. Other researchers found the same increase pattern in the process of heat treatment for various wood species (Esteves et al. 2007; Okon et al. 2017; Lee et al. 2018; Fu et al. 2019). The shrinkage in the tangential direction was higher than that in radial direction, whereas shrinkage in the radial direction was much higher than that in the longitudinal direction. The anisotropy was due to the wood structure and the arrangement of microfibrils in the cell wall (Gunduz et al. 2009; Dündar et al. 2012).

The lowest volume shrinkage ratio of the heat-treated $C$. fargesii wood at $215{ }^{\circ} \mathrm{C}$ with sand and vacuum media were $7.2 \%$ and $9.0 \%$, respectively. This result represented decreases of $37.7 \%$ and $21.8 \%$ for the sand and vacuum media, respectively, compared to the reference group. When $C$. fargesii wood was treated at $215^{\circ} \mathrm{C}$, the volume shrinkage ratio with sand heat treatment was $20.5 \%$ lower than that with vacuum heat treatment, whereas the volume shrinkage ratio with sand heat treatment at $185^{\circ} \mathrm{C}$ was slightly smaller than that with vacuum heat treatment at $215^{\circ} \mathrm{C}$. The ratio of shrinkage in the tangential direction to that in the radial direction was 2.7 for the $C$. fargesii wood of reference group, whereas it decreased to 2.0 and 2.2 after heat treatment at $215^{\circ} \mathrm{C}$ in the sand and vacuum media, respectively. The decrease of this ratio showed that the anisotropy of the $C$. fargesii wood decreased as temperature increased. Overall, the heat-treated $C$. fargesii wood with the sand medium has higher dimensional stability than that with the vacuum medium under the same process. The increase of dimension stability was caused by holocellulose decomposition. The ANOVA (Table 2.) showed that temperature and medium had significant effects on the tangential, radial, and volume shrinkage of the heat-treated $C$. fargesii wood $(\mathrm{p}<0.05)$.

Table 2. ANOVA of Shrinkage from Saturated State to Oven-dry State for Heattreated $C$. fargesii Wood under Different Temperatures and Media

\begin{tabular}{|c|c|c|c|c|c|c|c|c|}
\hline \multirow{2}{*}{ Factor } & \multicolumn{2}{|c|}{ Tangential } & \multicolumn{2}{c|}{ Radial } & \multicolumn{2}{c|}{ Longitudinal } & \multicolumn{2}{c|}{ Volume } \\
\cline { 2 - 9 } & $\mathrm{F}$ & Sig. & $\mathrm{F}$ & Sig. & $\mathrm{F}$ & Sig. & $\mathrm{F}$ & Sig. \\
\hline Medium & 60.437 & .000 & 27.289 & .000 & 16.193 & .000 & 46.842 & .000 \\
\hline Temperature & 28.889 & .000 & 24.514 & .000 & .841 & .476 & 31.103 & .000 \\
\hline $\begin{array}{c}\text { Medium* } \\
\text { Temperature }\end{array}$ & 1.544 & .209 & 2.958 & .037 & .255 & .857 & 2.388 & .074 \\
\hline
\end{tabular}

Qi et al. (2021). "Wood properties after heat treatment," BioResources 16(3), 5821-5837. 5826 

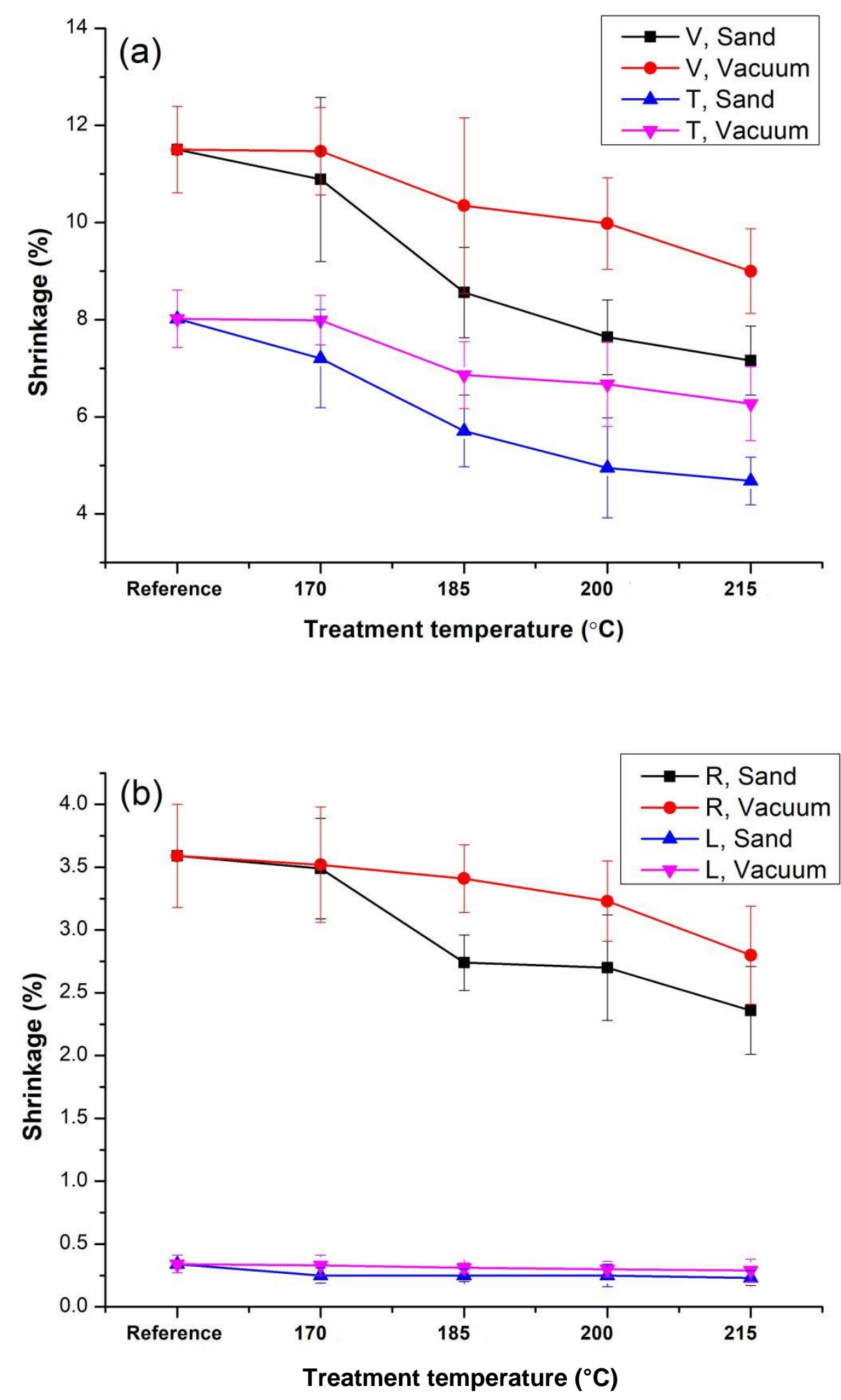

Fig. 2. Shrinkage from Saturated State to Oven-dry State of Heat-treated $C$. fargesii Wood under Different Temperatures and Media ( $\mathrm{a}$ is Shrinkage of Tangential $(\mathrm{T})$ and Volume $(\mathrm{V})$; $\mathrm{b}$ is Shrinkage of Radial $(\mathrm{R})$ and Longitudinal $(\mathrm{L}))$ 


\section{Color Analysis}

The change pattern of the heat-treated $C$. fargesii wood color traits $\left(L^{*}, a^{*}, b^{*}\right.$, and $\left.\triangle E^{*}\right)$ with temperature under different media is presented in Fig. 3. The lightness value $\left(L^{*}\right)$ of the heat-treated $C$. fargesii gradually decreased in both media as the temperature increased. At the same temperature, the lightness of the heat-treated wood was much smaller in the sand medium than the vacuum medium. The lightness of the $C$. fargesii before heat treatment was 74.8 . After heat treatment at $215^{\circ} \mathrm{C}$ for $4 \mathrm{~h}$, the lightness in the vacuum and sand media decreased to 19.45 and 43.88, respectively. The change pattern was similar to that reported by other researchers (Fan et al. 2010), wherein the $L^{*}$ value of wood decreased after heat treatment. According to the results of the variance analysis, the effects of heat treatment temperature and medium on $L^{*}$ were significant $(\mathrm{p}<0.05)$.

Figure 3 shows that there were two change patterns in the chroma $\left(a^{*}, b^{*}\right)$ for the heat-treated $C$. fargesii wood as temperature increased. Pattern 1 increased at first, which was followed by a decline. Pattern 2 was a consistent increase. In this study, the change pattern of $a^{*}$ and $b^{*}$ were in line with pattern 1 with sand heat treatment and pattern 2 with vacuum heat treatment. Both change patterns were previously reported (Bekhta and Niemz 2003; Mehmet et al. 2007; Fan et al. 2010; Okon et al. 2017). Before heat treatment, the $a^{*}$ value of the $C$. fargesii wood was 4.91 , and the $b^{*}$ value was 18.84 . Compared to the untreated wood, the increase ranges of $a^{*}$ and $b^{*}$ were $17 \%$ to $40 \%$ and $8.7 \%$ to $14.3 \%$ after vacuum heat treatment. The variation range of $b^{*}$ was $12 \%$ to $98 \%$, the increase range of $a^{*}$ was $8.5 \%$ to $9.2 \%$, and the decrease range of $a^{*}$ was $25.6 \%$ to $62.1 \%$ after sand heat treatment. The inflection point of chroma for the sand-heat-treated $C$. fargesii wood appeared at $185{ }^{\circ} \mathrm{C}$. The oxidation products, such as quinones, were produced during the heating process, and they absorbed the supplementary light of red. As the amount of such substances increased, the value of $a^{*}$ gradually increased. The increase of $b^{*}$ could be partly caused by the low-molecular-weight phenolic substances, which are pale yellow and formed during heat treatment (Yao et al. 2010). In addition, as the amount of these substances increased, the values of $a^{*}$ and $b^{*}$ gradually increased (Fan et al. 2010). According to Table 3, the effects of heat treatment temperature, medium, and the interaction on chroma value were significant $(\mathrm{p}<0.05)$.

The degree of color change of $C$. fargesii wood after heat treatment was characterized by the total color difference $\left(\Delta E^{*}\right)$. Figure 3 shows that $\Delta E^{*}$ increased as temperature increased with both media. The $\triangle E^{*}$ of the $C$. fargesii wood heat-treated in sand was larger than that treated in vacuum when the treatment process was same. After heat treatment at $215^{\circ} \mathrm{C}$ for $4 \mathrm{~h}$, the $\Delta E^{*}$ of $C$. fargesii wood was 45.52 and 19.63 with the sand and vacuum media, respectively. Notably, the $\Delta E^{*}$ of the heat-treated $C$. fargesii wood in vacuum at $215^{\circ} \mathrm{C}$ was the same as that treated in sand at $170{ }^{\circ} \mathrm{C}(21.33)$. Vacuum heat treatment always resulted in lower changes in color than sand heat treatment did in the same process. The darker color of heat-treated wood was mainly caused by the formation of degradation products from amorphous carbohydrates, changes in extractions, and the formation of oxygen products (Kačíková et al. 2013; Barcík et al. 2015). According to the ANOVA results, the effects of heat treatment temperature, medium, and the interaction on $\triangle E^{*}$ were extremely significant.

Overall, the effects of vacuum heat treatment at $215^{\circ} \mathrm{C}$ on the $\Delta E^{*}$ and $L^{*}$ of $C$. fargesii wood were similar to that of sand heat treatment at $170{ }^{\circ} \mathrm{C}$. The maximum values of $a^{*}$ and $b^{*}$ in the vacuum medium were close to those in the sand medium, which showed that the degradation of wood that was heat-treated in the vacuum medium was less severe 
than the sand medium. The temperature and medium had significant effects on the color characteristics of the heat-treated $C$. fargesii wood $(\mathrm{p}<0.05)$.
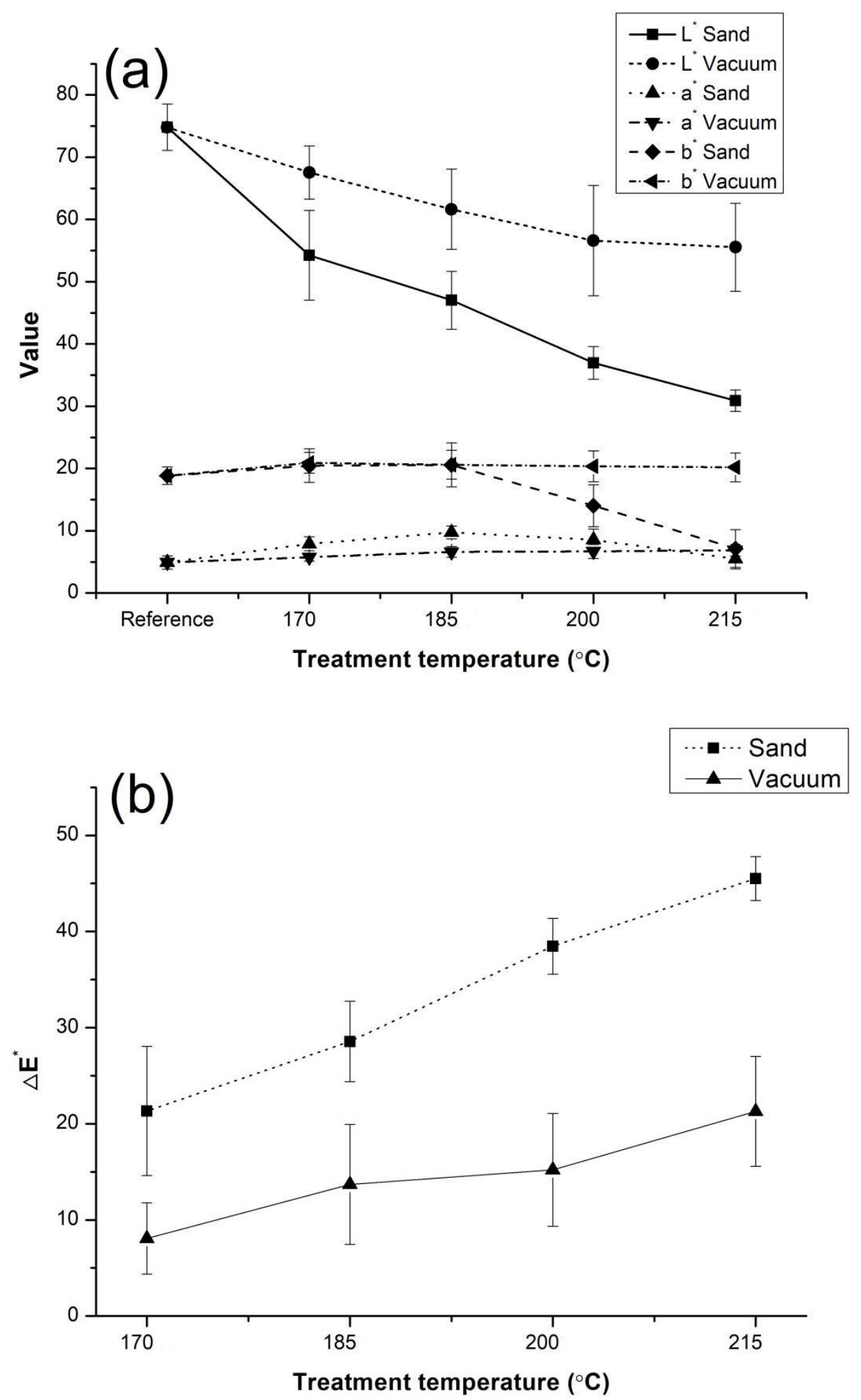

Fig. 3. $L^{*}, a^{*}, b^{*}(\mathrm{a})$ and $\triangle E^{*}$ (b) of the $C$. fargesii wood under different heat treatment temperatures and media 
Table 3. Variance Analysis of Color Characters for Heat-treated C. fargesii Wood under Different Temperatures and Media

\begin{tabular}{|c|c|c|c|c|c|c|c|c|}
\hline \multirow{2}{*}{ Factor } & \multicolumn{2}{|c|}{$\boldsymbol{L}^{\boldsymbol{*}}$} & \multicolumn{2}{c|}{$\boldsymbol{a}^{\boldsymbol{*}}$} & \multicolumn{2}{c|}{$\boldsymbol{b}^{\boldsymbol{*}}$} & \multicolumn{2}{c|}{$\Delta \boldsymbol{E}^{\boldsymbol{*}}$} \\
\cline { 2 - 9 } & $\mathrm{F}$ & Sig. & $\mathrm{F}$ & Sig. & $\mathrm{F}$ & Sig. & $\mathrm{F}$ & Sig. \\
\hline Treatment & 252.503 & .000 & 40.713 & .000 & 74.616 & .000 & 360.073 & .000 \\
\hline Temperature & 44.521 & .000 & 15.636 & .000 & 30.165 & .000 & 57.419 & .000 \\
\hline $\begin{array}{c}\text { Treatment } \\
\text { Temperature }\end{array}$ & 4.629 & .004 & 16.56 & .000 & 25.424 & .000 & 7.878 & .000 \\
\hline
\end{tabular}

\section{Chemical Properties of Thermally Modified Wood}

\section{Chemical composition analysis}

The changes in the holocellulose, cellulose, and lignin of the heat-treated C. fargesii wood at different temperatures and media are presented in Table 4. As temperature increased, the lignin content increased and the content of holocellulose decreased. The chemical differences of the heat-treated $C$. fargesii wood in the sand and vacuum media were the degrees of holocellulose degradation and the change patterns of cellulose.

The holocellulose contents in the heat-treated $C$. fargesii wood in both the sand and vacuum media decreased as the temperature increased, and the decreased degree of holocellulose in the sand medium was much higher than that with the vacuum medium. The decrease in holocellulose was mainly caused by the degradation of hemicellulose. Hemicellulose is the first part of degradation due to its lower thermal stability, as hemicellulose has no crystal region (Mburu et al. 2008). Acetyl groups are an important factor, since they facilitate thermal degradation of hemicellulose. They are thermally labile and lead to the formation of acetic acid, thereby causing acid-catalysed degradation of the polysaccharides. Acid-catalysed reactions result in the formation of formaldehyde, 2furaldehyde, and other aldehydes (Okon et al, 2017). Acetic acid and other small molecular volatiles produced during heat treatment can further promote the degradation of hemicellulose. However, in the process of vacuum heat treatment, these substances were extracted, while in the process of sand heat treatment, these volatiles were released slowly, which further promoted the degradation of hemicellulose.

The cellulose content in the heat-treated $C$. fargesii wood decreased compared to the reference group when it was heated to $170{ }^{\circ} \mathrm{C}$ in both media. This may have occurred because the non-crystalline region of cellulose was degraded. However, as the temperature continued to increase, the crystalline region in cellulose provided stability to the cellulose chains and protected them against acid attack during hydrolysis. However, hemicellulose continued to degrade, so the cellulose content increased a small amount. The relative cellulose content has been shown to increase after heat treatment (Severo et al. 2012). Brito et al. (2008) studied the heat treatment of eucalyptus and Pinus and observed that the content of glucose as the cellulose constituent slightly increased, which reflected an increase in cellulose content. When the $C$. fargesii wood was heated in the sand medium at $215{ }^{\circ} \mathrm{C}$, the cellulose content decreased, which was consistent with the decrease in cellulose crystallinity observed in the XRD analysis. At high heat treatment temperature, depolymerization occurs in both the crystalline and noncrystalline regions, the degradation of cellulose is intense, so the relative content of cellulose decreased.

Qi et al. (2021). "Wood properties after heat treatment," BioResources 16(3), 5821-5837. 5830 
The acid-insoluble lignin content in the heat-treated $C$. fargesii wood in both the sand and vacuum media increased as temperature increased. Compared with the reference group, the lignin content of the heat-treated $C$. fargesii wood increased from $17.2 \%$ to $42.7 \%$ and $28.62 \%$ in the sand and vacuum media, respectively, at $215^{\circ} \mathrm{C}$. This occurred because the reduction in polysaccharides was higher than that in lignin. In addition, hemicellulose degrades thermally approximately four times faster than wood, whereas lignin degrades approximately half as fast as wood (Stamm 1956; Kačíková et al. 2013). Alternatively, this increase may have come from the condensation reactions of carbohydrates, which would have increased the amount of acid-insoluble material in heattreated wood.

Table 4. The Components of the $C$. fargesii Wood under Different Heat Treatment Temperatures and Media

\begin{tabular}{|c|c|c|c|c|c|c|c|}
\hline \multirow{2}{*}{ Heat Condition } & \multicolumn{2}{|c|}{$\begin{array}{c}\text { Holocellulose } \\
\text { (\%) }\end{array}$} & \multicolumn{2}{c|}{ Cellulose (\%) } & \multicolumn{2}{c|}{ Lignin (\%) } \\
\cline { 2 - 7 } \multicolumn{2}{|c|}{ Mean } & SD & Mean & SD & Mean & SD \\
\hline \multicolumn{2}{|c|}{ Reference } & 80.49 & 0.48 & 48.0 & 0.49 & 17.62 & 0.72 \\
\hline \multirow{3}{*}{ Sand } & $170^{\circ} \mathrm{C}$ & 72.36 & 0.60 & 45.7 & 0.08 & 24.83 & 1.63 \\
\cline { 2 - 8 } & $185^{\circ} \mathrm{C}$ & 63.38 & 0.09 & 46.2 & 0.92 & 25.20 & 0.75 \\
\cline { 2 - 8 } & $200^{\circ} \mathrm{C}$ & 57.18 & 2.4 & 48.8 & 0.84 & 31.44 & 0.81 \\
\cline { 2 - 8 } & $215^{\circ} \mathrm{C}$ & 51.04 & 0.05 & 44.8 & 0.03 & 42.87 & 0.30 \\
\hline Vacuum & $170^{\circ} \mathrm{C}$ & 72.98 & 0.16 & 45.38 & 1.49 & 25.20 & 3.26 \\
\cline { 2 - 8 } & $185^{\circ} \mathrm{C}$ & 72.11 & 0.30 & 46.4 & 0.42 & 26.19 & 0.20 \\
\cline { 2 - 8 } & $200^{\circ} \mathrm{C}$ & 69.97 & 0.99 & 46.77 & 0.39 & 28.16 & 1.05 \\
\cline { 2 - 8 } & $215^{\circ} \mathrm{C}$ & 69.43 & 0.79 & 51.12 & 0.79 & 28.62 & 0.14 \\
\hline
\end{tabular}

\section{FTIR Analysis}

The FTIR spectra of the heat-treated $C$. fargesii wood in both media and the reference group are presented in Fig. 4. The peak at $1737 \mathrm{~cm}^{-1}$ was attributed to the stretch vibration of $\mathrm{C}=\mathrm{O}$, which belongs to carbonyl, carboxyl, and acetyl. The decrease at this peak indicates a decrease in hemicellulose content. The increase in the intensity of the band at $1510 \mathrm{~cm}^{-1}$ was assigned to the $\mathrm{C}=\mathrm{C}$ stretching of the aromatic skeletal components in lignin with both media. This indicated an increase in the amount of lignin in the wood, and the degradation of amorphous carbohydrates occurred. The peak at $1232 \mathrm{~cm}^{-1}$ was assigned to the $\mathrm{C}-\mathrm{O}$ stretching vibration coupled with the aromatic ring vibration in lignin and the $\mathrm{C}-\mathrm{O}$ stretching vibration in xyloglucan.

The increase in the intensity of the band at $1054 \mathrm{~cm}^{-1}$, which was assigned to the $\mathrm{C}-\mathrm{O}$ stretching vibrations in cellulose and hemicellulose, indicated the formation of aliphatic alcohols during heat treatment. This may have led to the percentage increase in crystalline cellulose, which indicated that dehydration occurred, and a large number of hydroxyl groups were lost in cellulose and hemicellulose during heat treatment. The band at $1033 \mathrm{~cm}^{-1}$, which was assigned to the $\mathrm{C}-\mathrm{O}$ ester stretching vibrations in methoxy and the $\beta-\mathrm{O}-4$ linkages in lignin, increased. This indicated that the cleavage of $\beta-\mathrm{O}-4$ linkages and splitting of the methoxy groups from the lignin structure occurred. The degradation

Qi et al. (2021). "Wood properties after heat treatment," BioResources 16(3), 5821-5837. 5831 
reaction of the cleavage of $\beta-\mathrm{O}-4$ linkages in lignin is catalyzed by acetic acid, which is formed and released from the degradation of acetyl groups in hemicellulose. The acetic acid can also catalyze other degradation reactions in the wood components (Li et al. 2015; Özgenç et al. 2016; Liu et al. 2017; Hoseinzadeh et al. 2019). The peaks at 1724, 1372, and other peaks related to holocellulose groups decreased or disappeared, while the peaks at $1510,1033 \mathrm{~cm}^{-1}$ and other peaks related to lignin groups increased. This result is the same as the result of chemical composition determination. After heat treatment, the holocellulose content of $C$. fargesii wood decreased while the lignin content of $C$. fargesii wood increased.

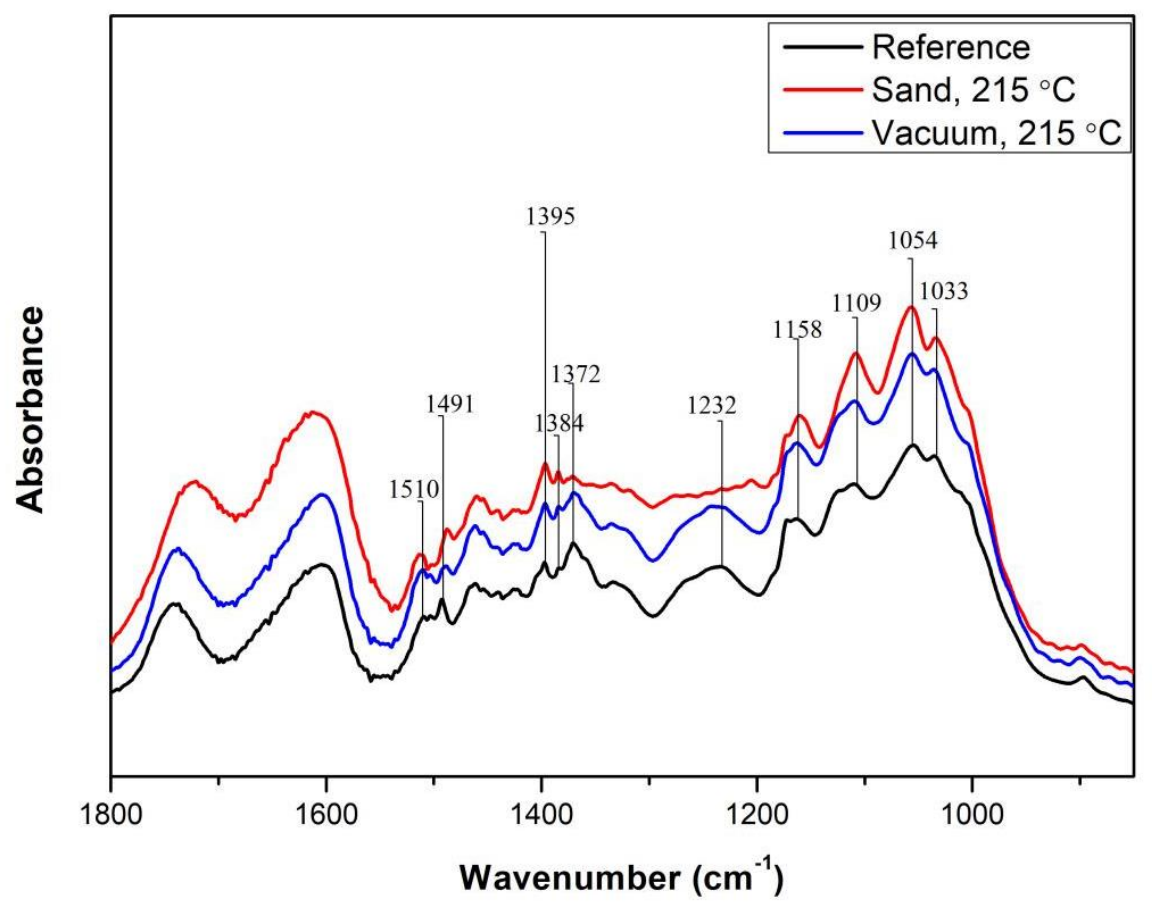

Fig. 4. FTIR spectra of $C$. fargesii wood under different heat treatment media

\section{XRD Analysis}

The CrI of the $C$. fargesii wood before and after heat treatment is shown in Table 5. As temperature increased, the $\mathrm{CrI}$ of the vacuum-heat-treated C. fargesii wood gradually increased, whereas that of the sand-heat-treated C. fargesii wood increased before $200{ }^{\circ} \mathrm{C}$ but slightly decreased at $215^{\circ} \mathrm{C}$. The change in moisture content causes changes in bond configuration of the noncrystalline regions of adjacent cellulose molecules and polyoses, resulting in swelling and shrinking. The increase in CrI indicates a decrease in the amorphous region, so the change in the CrI could explain that the shrinkage ratio of heattreated C. fargesii wood decreased as temperature increased (Akgül et al. 2007).

There are two explanations for the increase in crystallinity. First, it could have been due to the degradation of amorphous regions. In addition, the increased crystallization in the wood likely contributed. As the non-crystalline region degraded thermally, the relative crystalline content in the wood increased. The increase in crystallinity could have been because of crystallization in the quasi-crystalline amorphous regions due to the rearrangement or reorientation of cellulose molecules inside them. Wood cellulose contains more quasi-crystalline regions than pure cellulose because crystals in hemicellulose, xylan, and mannan are capable of crystallizing during heat treatment 
(Bhuiyan et al. 2000; Akgül et al. 2007; Yin et al. 2016). At the later stages of heat treatment, depolymerization occurs in both the crystalline and amorphous regions, the cellulose macromolecular chain breaks, the glucosidic linkage is cut, and decreases in crystallinity and polymerization appear (Bhuiyan et al. 2000).

Table 5. Crl of $C$. fargesii Wood Under Different Heat Treatment Temperatures and Media

\begin{tabular}{|c|c|}
\hline Factor & Crl (\%) \\
\hline Reference & $39.73 \pm 0.78$ \\
\hline Sand, $170^{\circ} \mathrm{C}$ & $42.15 \pm 1.57$ \\
\hline Sand, $185^{\circ} \mathrm{C}$ & $45.57 \pm 1.07$ \\
\hline Sand, $200^{\circ} \mathrm{C}$ & $49.37 \pm 0.18$ \\
\hline Sand, $215^{\circ} \mathrm{C}$ & $45.43 \pm 0.90$ \\
\hline Vacuum, $170^{\circ} \mathrm{C}$ & $40.28 \pm 0.35$ \\
\hline Vacuum, $185^{\circ} \mathrm{C}$ & $41.57 \pm 1.42$ \\
\hline Vacuum, $200^{\circ} \mathrm{C}$ & $42.87 \pm 1.2$ \\
\hline${\text { Vacuum, } 215^{\circ} \mathrm{C}}$ & $46.01 \pm 0.80$ \\
\hline
\end{tabular}

\section{TGA Analysis}

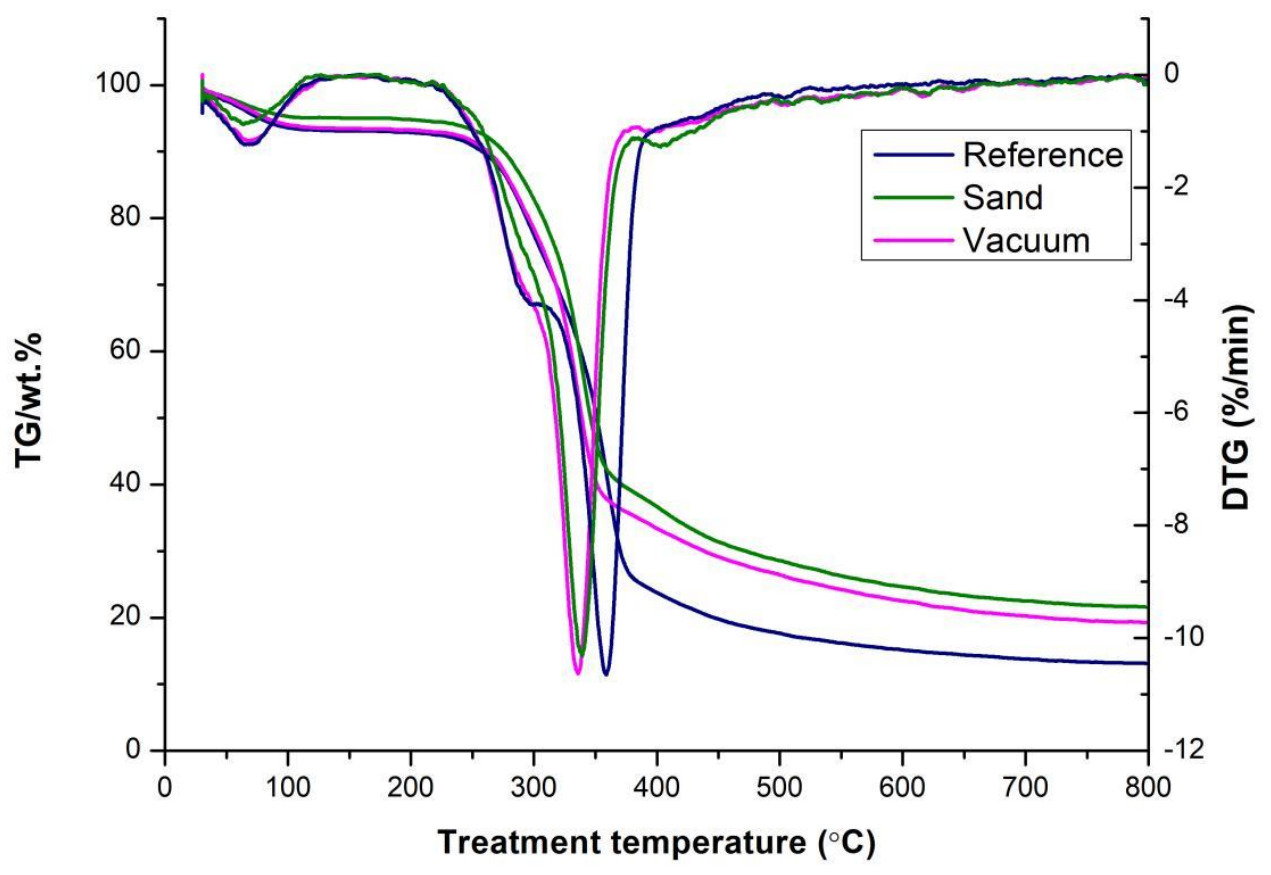

Fig. 5. TG and DTG curves of reference, sand and vacuum heat-treated $C$. fargesii wood

TG and DTG curves can be seen from Fig. 5. The final mass gradually increased, followed by reference $(13.14 \%)$, vacuum heat treated $(19.27 \%)$, and sand heat treated $(21.61 \%)$. The pyrolysis process of wood is essentially the pyrolysis of the main chemical components in wood. Compared with cellulose and hemicellulose, the pyrolysis process of 
lignin tends to form more coke, high carbon residue rate indicates high lignin content. Which confirmed that the degradation of wood that was heat-treated in the vacuum medium was less severe than the sand medium (Yuan et al. 2020).

\section{CONCLUSIONS}

1. When heated at same temperature and for the same duration, the dimensional stability of the heated $C$. fargesii wood in the sand medium was higher than that in the vacuum medium, and its color was darker.

2. A marked change in oven-dry density appeared after $200{ }^{\circ} \mathrm{C}$ for sand-heat treatment. The volume shrinkage of the heat-treated $C$. fargesii wood in the vacuum medium at $215^{\circ} \mathrm{C}$ was quite similar to that in the sand medium at $185^{\circ} \mathrm{C}$.

3. The change pattern of color traits for the heat-treated $C$. fargesii wood varied across the different media, and two change patterns of chroma $\left(a^{*}, b^{*}\right)$ were observed. The $\Delta E^{*}$ value of the heat-treated $C$. fargesii wood in the sand medium at $170{ }^{\circ} \mathrm{C}$ was quite similar to that in the vacuum medium at $215^{\circ} \mathrm{C}$.

4. The degree of change in chemical content for the heat-treated C. fargesii wood in the sand medium was much higher than that in the vacuum medium, which was also observed via FTIR and XRD.

5. The analysis of chemical contents showed that $C$. fargesii wood in the sand medium degraded heavier than that in the vacuum medium. The difference in thermal $C$. fargesii wood properties between samples treated in the sand and vacuum media were mainly caused by volatile content. During the process of wood heat treatment, the volatility remained in the heat environment in the sand medium, whereas it was released from the heat environment in the vacuum medium.

\section{ACKNOWLEDGMENTS}

This research was supported by the Natural Science Foundation of China (No. 31760191), the Fujian Province Major Science and Technology Project (No. 2018S0026), and the Technology Innovation Fund Project of Fujian Agriculture and Forestry University (No. CXZX2017479).

\section{REFERENCES CITED}

Akgül, M., Gümüskaya, E., and Korkut, S. (2007). "Crystalline structure of heat-treated Scots pine [Pinus sylvestris L.] and Uludağ fir [Abies nordmanniana (Stev.) subsp. bornmuelleriana (Mattf.)] wood," Wood Science and Technology 41(3), Article Number 281. DOI: 10.1007/s00226-006-0110-9

Altgen, M., Willems, W., Hosseinpourpia, R., and Rautkari, L. (2018). "Hydroxyl accessibility and dimensional changes of Scots pine sapwood affected by alterations in the cell wall ultrastructure during heat-treatment," Polymer Degradation and Stability 152, 244-252. DOI: 10.1016/j.polymdegradstab.2018.05.005 
Barcík, Š., Gašparík, M., and Razumov, E. (2015). "Effect of thermal modification on the colour changes of oak wood," Wood Research 60(3), 385-396.

Bekhta, P., and Niemz, P. (2003). "Effect of high temperature on the change in color, dimensional stability and mechanical properties of spruce wood," Holzforschung 57(5), 539-546. DOI: 10.1515/HF.2003.080

Bhuiyan, M. T. R., Hirai, N., and Sobue, N. (2000). "Changes of crystallinity in wood cellulose by heat treatment under dried and moist conditions," Journal of Wood Science 46(6), 431-436. DOI: 10.1007/BF00765800

Brito, J. O., Silva, F. G., Leão, M. M., and Almeida, G. (2008). "Chemical composition changes in eucalyptus and pinus woods submitted to heat treatment," Bioresource Technology 99(18), 8545-8548. DOI: 10.1016/j.biortech.2008.03.069

Candelier, K., Dumarçay, S., Pétrissans, A., Desharnais, L., Gérardin, P., and Pétrissans, M. (2012). "Comparison of chemical composition and decay durability of heat-treated wood cured under different inert atmospheres: Nitrogen or vacuum," Polymer Degradation and Stability 98(2), 677-681. DOI:

10.1016/j.polymdegradstab.2012.10.022

Candelier, K., Dumarçay, S., Pétrissans, A., Gérardin, P., and Pétrissans, M. (2013) "Comparison of mechanical properties of heat-treated beech wood cured under nitrogen or vacuum," Polymer Degradation \& Stability 98(9), 1762-1765. DOI: 10.1016/j.polymdegradstab.2013.05.026

Dündar, T., Büyüksarı, Ü., Avcı, E., and Akkılıç, H. (2012). "Effect of heat treatment on the physical and mechanical properties of compression and opposite wood of black pine," BioResources 7(4), 5009-5018. DOI: 10.15376/biores.7.4.5009-5018

Esteves, B. M., and Pereira, H. M. (2009). "Wood modification by heat treatment: A review," BioResources 4(1), 370-404. DOI: 10.15376/biores.4.1.370-404

Esteves, B., Velez Marques, A., Domingos, I., and Pereira, H. (2007). "Influence of steam heating on the properties of pine (Pinus pinaster) and eucalypt (Eucalyptus globulus) wood," Wood Science and Technology 41(3), Article Number 193. DOI: 10.1007/s00226-006-0099-0

Fan, Y., Gao, J., and Chen, Y. (2010). "Colour responses of black locust (Robinia pseudoacacia L.) to solvent extraction and heat treatment," Wood Science and Technology 44(4), 667-678. DOI: 10.1007/s00226-009-0289-7

Fu, Z., Zhou, Y., Gao, X., Liu, H., and Zhou, F. (2019). “Changes of water related properties in radiata pine wood due to heat treatment," Construction and Building Materials 227, Article ID 116692. DOI: 10.1016/j.conbuildmat.2019.116692

Gunduz, G., Aydemir, D., and Karakas, G. (2009). "The effects of thermal treatment on the mechanical properties of wild pear (Pyrus elaeagnifolia Pall.) wood and changes in physical properties," Materials \& Design 30(10), 4391-4395. DOI:

10.1016/j.matdes.2009.04.005

GB/T 1933-2009 Chinese Standard of Method for determination of density of wood. The people's Republic of China, Beijing, China

GB/T 1932-2009 Chinese Standard of Method for determination of shrinkage of wood. The people's Republic of China, Beijing, China

GB/T 2677.8-94 Chinese Standard of Fiber raw material-Determination of acid-insoluble lignin. The people's Republic of China, Beijing, China

GB/T 2677.10-1995 Chinese Standard of Fiber raw material-Determination of holocellulose. The people's Republic of China, Beijing, China

GB/T 744-1989 Chinese Standard of Pulps-Determination of a-cellulose. The people's

Qi et al. (2021). "Wood properties after heat treatment," BioResources 16(3), 5821-5837. 5835 
Republic of China, Beijing, China

Guo, J., Song, K., Salmén, L., and Yin, Y. (2015). "Changes of wood cell walls in response to hygro-mechanical steam treatment," Carbohydrate Polymers 115, 207 214. DOI: 10.1016/j.carbpol.2014.08.040

Hoseinzadeh, F., Zabihzadeh, S. M., and Dastoorian, F. (2019). "Creep behavior of heattreated beech wood and the relation to its chemical structure," Construction and Building Materials 226, 220-226. DOI: 10.1016/j.conbuildmat.2019.07.181

Kačíková, D., Kačík, F., Čabalová, I., and Ďurkovič, J. (2013). “Effects of thermal treatment on chemical, mechanical and colour traits in Norway spruce wood," Bioresource Technology 144, 669-674. DOI: 10.1016/j.biortech.2013.06.110

Kubojima, Y., Okano, T., and Ohta, M. (2000). "Bending strength and toughness of heattreated wood," Journal of Wood Science 46(1), 8-15. DOI: 10.1007/BF00779547

Lee, S. H., Ashaari, Z., Lum, W. C., Ang, A. F., Halip, J. A., and Halis, R. (2018). "Chemical, physico-mechanical properties and biological durability of rubberwood particleboards after post heat-treatment in palm oil," Holzforschung 72(2), 159-167. DOI: $10.1515 / \mathrm{hf}-2017-0086$

Li, M.-Y., Cheng, S.-C., Li, D., Wang, S.-N., Huang, A.-M., and Sun, S.-Q. (2015). "Structural characterization of steam-heat-treated Tectona grandis wood analyzed by FT-IR and 2D-IR correlation spectroscopy," Chinese Chemical Letters 26(2), 221225.

Li, T., Cheng, D., Avramidis, S., Wålinder, M. E. P., and Zhou, D. (2017). "Response of hygroscopicity to heat treatment and its relation to durability of thermally modified wood," Construction and Building Materials 144, 671-676. DOI: 10.1016/j.conbuildmat.2017.03.218

Lin, Y., Qiu, R., Yao, J., Hu, X., and Lin, J. (2019). "The effects of urbanization on China's forest loss from 2000 to 2012: Evidence from a panel analysis," Journal of Cleaner Production 214, 270-278. DOI: 10.1016/j.jclepro.2018.12.317

Liu, X. Y., Timar, M. C., and Varodi, A. M. (2017). "An investigation of accelerated temperature-induced ageing of four wood species: Colour and FTIR," Wood Science and Technology 51(2), 357-378. DOI: 10.1007/s00226-016-0867-4

Liu, Z. H. (2010). "Structure of Castanopsis wood and its influence on wood drying," China Forest Products Industry 37(3), 16-19.

Mburu, F., Dumarçay, S., Bocquet, J. F., Petrissans, M., and Gérardin, P. (2008). "Effect of chemical modifications caused by heat treatment on mechanical properties of Grevillea robusta wood," Polymer Degradation and Stability 93(2), 401-405. DOI: 10.1016/j.polymdegradstab.2007.11.017

Okon, K. E., Lin, F., Chen, Y., and Huang, B. (2017). "Effect of silicone oil heat treatment on the chemical composition, cellulose crystalline structure and contact angle of Chinese parasol wood," Carbohydrate Polymers 164, 179-185. DOI: 10.1016/j.carbpol.2017.01.076

Özgenç, O., Durmaz, S., Boyaci, I. H., and Eksi-Kocak, H. (2016). "Determination of chemical changes in heat-treated wood using ATR-FTIR and FT-Raman spectrometry," Spectrochimica Acta Part A: Molecular and Biomolecular Spectroscopy 171, 395-400. DOI: 10.1016/j.saa.2016.08.026

Rautkari, L., Honkanen, J., Hill, C. A. S., Ridley-Ellis, D., and Hughes, M. (2014). "Mechanical and physical properties of thermally modified scots pine wood in high pressure reactor under saturated steam at 120, 150 and $180{ }^{\circ} \mathrm{C}$," European Journal of Wood \& Wood Products 72(1), 33-41. DOI: 10.1007/s00107-013-0749-5 
Segal, L., Creely, J. J., Martin, A. E., and Conrad, C. M. (1959). “An empirical method for estimating the degree of crystallinity of native cellulose using the X-ray diffractometer," Textile Research Journal 29(10), 786-794. DOI: 10.1177/004051755902901003.

Severo, E. T. D., Calonego, F. W., and Sansígolo, C. A. (2012). "Physical and chemical changes in juvenile and mature woods of Pinus elliottii by thermal modification," European Journal of Wood and Wood Products 70(5), 741-747. DOI: 10.1007/s00107-012-0611-1

Stamm, A. J. (1956). “Thermal degradation of wood and cellulose," Industrial \& Engineering Chemistry 48(3), 413-417. DOI: 10.1021/ie51398a022

Sun, B., Wang, X., and Liu, J. (2013). "Changes in dimensional stability and mechanical properties of Eucalyptus pellita by melamine-urea-formaldehyde resin impregnation and heat treatment," European Journal of Wood and Wood Products 71(5), 557-562. DOI: $10.1007 / \mathrm{s} 00107-013-0700-9$

Wang, X. H., Liu, J. L., Xu, G. Q., and Chai, Y. B. (2011). "Microstructure of Eucalyptus pellita under different thermal treatment temperatures and its effect on physicalmechanical characteristic," Advanced Materials Research 214, 544-548. DOI: 10.4028/www.scientific.net/AMR.214.544

Yang, T.-H., Lee, C.-H., Lee, C.-J., and Cheng, Y.-W. (2016). "Effects of different thermal modification media on physical and mechanical properties of moso bamboo," Construction and Building Materials 119, 251-259. DOI: 10.1016/j.conbuildmat.2016.04.156

Yao, C., Yongming, F., Jianmin, G., and Houkun, L. (2010). "Coloring characteristics of in situ lignin during heat treatment," Wood Science and Technology, 46(1-3), 3340. DOI:10.1007/s00226-010-0388-5

Yin, J., Yuan, T., Lu, Y., Song, K., and Yin, Y. (2016). "Effect of compression combined with steam treatment on the porosity, chemical composition and cellulose crystalline structure of wood cell walls," Carbohydrate Polymers 155, 163-172. DOI: 10.1016/j.carbpol.2016.08.013

Yuan, C., Zhai, S.-C., Zhang, Y.-M., and Zhang, Y.-L. (2020). "Simple evaluation of degradation state of archaeological wood based on the infrared spectroscopy combined with thermogravimetry," Spectroscopy and Spectral Analysis 40(9), 29432950. DOI: 10.3964/j.issn. 1000-0593(2020)09-2943-08

Article submitted: March 23, 2021; Peer review completed: May 31, 2021; Revised version received and accepted: June 28, 2021; Published: July 6, 2021.

DOI: 10.15376/biores.16.3.5821-5837 